\title{
ABDOMINAL TROPHALLAXIS IN THE SLAVE-MAKING \\ ANT, HARPAGOXENUS AMERICANUS
}

(HYMENOPTERA: FORMICIDAE)*

\author{
Robin J. STUART \\ Department of Zoology, Erindale College, \\ University of Toronto, \\ Mississauga, Ontario, L5L 1C6 Canada
}

\begin{abstract}
Abdominal trophallaxis refers to the passage of fluids from the abdominal tip of one individual to the mouthparts of another. It is common among lower termites (Kalotermitidae and Rhinotermitidae) where it functions in the vital transmission of intestinal flagellates to newly molted individuals. However, it has rarely been documented among ants (Wilson, 1971, 1976). By strict definition, the term abdominal trophallaxis should be applied only when alimentary fluid is being transmitted (Wilson, 1971). Nevertheless, in practice, the origin of the fluid is often unknown, at least initially. Indeed, in all cases where this behavior has been described in ants, the fluid is either suspected of being, or has since been shown to be, ovarian in nature. For example, workers of certain Eciton species (Dorylinae) readily feed from droplets secreted from the tip of the queen's abdomen, but this behavior has been observed only during egg-laying bouts (Schneirla, 1944; Rettenmeyer, 1963). So-called "proctodeal feeding" has also been described among the Dolichoderinae (Dolichoderus quadripunctatus, Tapinoma erraticum and Iridomyrmex humilis) (Torossian, 1958, 1959, 1960, 1961). However, at least in the case of $D$. quadripunctatus, the fluid has been identified as the yolky remnants of abortive trophic eggs (Torossian, 1978, 1979). Among the Myrmicinae, Zacryptocerus varians exhibits a similar behavior which is also thought to be associated with egg-laying (Wilson, 1976). This paper reports an unusual and interesting case of abdominal trophallaxis in colonies of the socially parasitic myrmicine ant, Harpagoxenus americanus. I have followed Wilson (1976) and tentatively applied the term abdominal trophallaxis, because the origin of the fluid is unknown.

$H$. americanus is an obligatory slave-maker and forms mixed colonies with members of certain Leptothorax species in eastern
\end{abstract}

*Manuscript received by the editor November 10, 1981. 
North America (Alloway, 1979). The observations reported here took place in artificial nests in the laboratory (Alloway, 1979) and utilized colonies of $H$. americanus containing one or both of its host species, $L$. ambiguus and $L$. longispinosus. The colonies were collected in the regional municipalities of Halton and Peel, Ontario.

Intermittent observations of activity inside $H$. americanus nests revealed that slave-maker queens and workers occasionally convey fluids to their slaves by means of abdominal trophallaxis. Donors characteristically raise their abdomens and assume a stereotyped posture, similar to that seen during "sexual calling" ("Locksterzeln") in other leptothoracine ants (Buschinger and Alloway, 1979). I was unable to ascertain whether the sting is exposed in the present context, as it is during "sexual calling" and "tandem calling", a similar behavior used during nest-mate recruitment in some leptothoracine ants (Moglich et al., 1974). While maintaining this posture, the donor secretes a droplet of clear fluid from the tip of her abdomen, and holds it there, at times for several minutes. Slaves do not seem to be attracted from any appreciable distance by this behavior, but those close by turn and antennate the donor's abdomen, apply their mouthparts to the tip, and consume the droplet. As many as three slaves have been observed to attend a donor simultaneously in this manner, clustered about her abdominal tip and attempting to consume the droplet. On one occasion, the droplet was removed from the donor's abdomen by three workers in concert, held between their mandibles momentarily, and then consumed. Once the droplet is removed, the donor lowers her abdomen, and both donor and recipients appear to resume normal activities. There is no indication that slaves ever solicit this fluid; and to date, the reverse, slaves donating to slave-makers, has not been observed. Similarly, this behavior has never been observed in laboratory colonies of the host species. The nature of the fluid transmitted is unknown. It may be ovarian in origin, since $H$. americanus workers will lay eggs, even in queenright colonies (Buschinger and Alloway, 1977). The frequency of this behavior is uncertain. It appears to be rare, since frequent observations of colonies for other purposes have seldom encountered it. However, no detailed behavioral repertoire study of this ant has been conducted.

The fact that $H$. americanus employs a characteristic posture during abdominal trophallaxis suggests that this behavior may have 
important biological consequences. Furthermore, the apparent absence of this behavior in free-living leptothoracine ants, and the fact that transmission is consistently from slave-maker to slave, suggests that abdominal trophallaxis may in some way contribute to this species' particular socially parasitic relationship. The discovery of this behavior in a slave-making ant opens a previously unknown avenue for consideration in discussions of the means by which slavemakers may affect the behavior of their slaves.

\section{ACKNOWLEDGMENTS}

I thank T.M. Alloway for his comments on the manuscript. Financial assistance was provided by an Ontario Graduate Scholarship to the author, and a grant from the Natural Sciences and Engineering Research Council of Canada to T.M. Alloway.

\section{Literature Cited}

Alloway, T. M. 1979. Raiding behaviour of two species of slave-making ants, Harpagoxenus americanus (Emery) and Leptothorax duloticus Wesson (Hymenoptera: Formicidae). Anim. Behav. 27: 202-210.

Buschinger, A., ANd T. M. Alloway. 1977. Population structure and polymorphism in the slave-making ant Harpagoxenus americanus (Emery) (Hymenoptera: Formicidae). Psyche 83: 233-242.

1979. Sexual behaviour in the slave-making ant Harpagoxenus canadensis $\mathrm{M}$. R. Smith, and sexual pheromone experiments with $H$. canadensis, $H$. americanus (Emery), and $H$ sublaevis (Nyl.) (Hymenoptera: Formicidae). Z. Tierpsychol. 49: 113-119.

Moglich, M., U. Maschwitz, and B. Holldobler. 1974. Tandem calling: a new kind of signal in ant communication. Science 186: 1046-1047.

RetTenmeyer, C. W. 1963. Behavioral studies of army ants. Kan. Univ. Sci. Bull. 44: $281-465$.

SchneIRla, T. C. 1944. The reproductive functions of the army-ant queen as pace-makers of the group behavior pattern. J. N. Y. Entomol. Soc. 52: 153-192.

Torossian, C. 1958. L'aliment proctodeal chez la fourmi Dolichoderus quadripunctatus (Dolichoderidae). C. R. Acad. Sci. 246: 3524-3526.

1959. Les echanges trophallactiques proctodeaux chez la fourmi Dolichoderus quadripunctatus (Hymenoptere-Formicoidea). Ins. Soc. 6: 369-374.

1960. Les echanges trophallactiques proctodeaux chez la fourmi Tapinoma erraticum. Ins. Soc. 7: 174-175.

1961. Les echanges trophallactiques proctodeaux chez la fourmi d'Argentine: Iridomyrmex humilis (Hym. Form. Dolichoderidae). Ins. Soc.

8: $189-191$. 
1978. La ponte d'oeufs abortifs chez les ouvrieres de la fourmi Dolichoderus quadripunctatus. Soc. Hist. Nat. Toulouse Bull. 114: 207-211.

1979. Importance quantitative des oeufs abortifs d'ouvrieres dan le bilan trophique de la colonie de la fourmi Dolichoderus quadripunctatus. Ins. Soc. 26: 295-299.

Wilson, E. O. 1971. The insect societies. Harvard Univ. Press, Cambridge, Mass. $\mathrm{x}+548 \mathrm{pp}$.

1976. A social ethogram of the neotropical arboreal ant Zacryptocerus varians (Fr. Smith). Anim. Behav. 24: 354-363. 

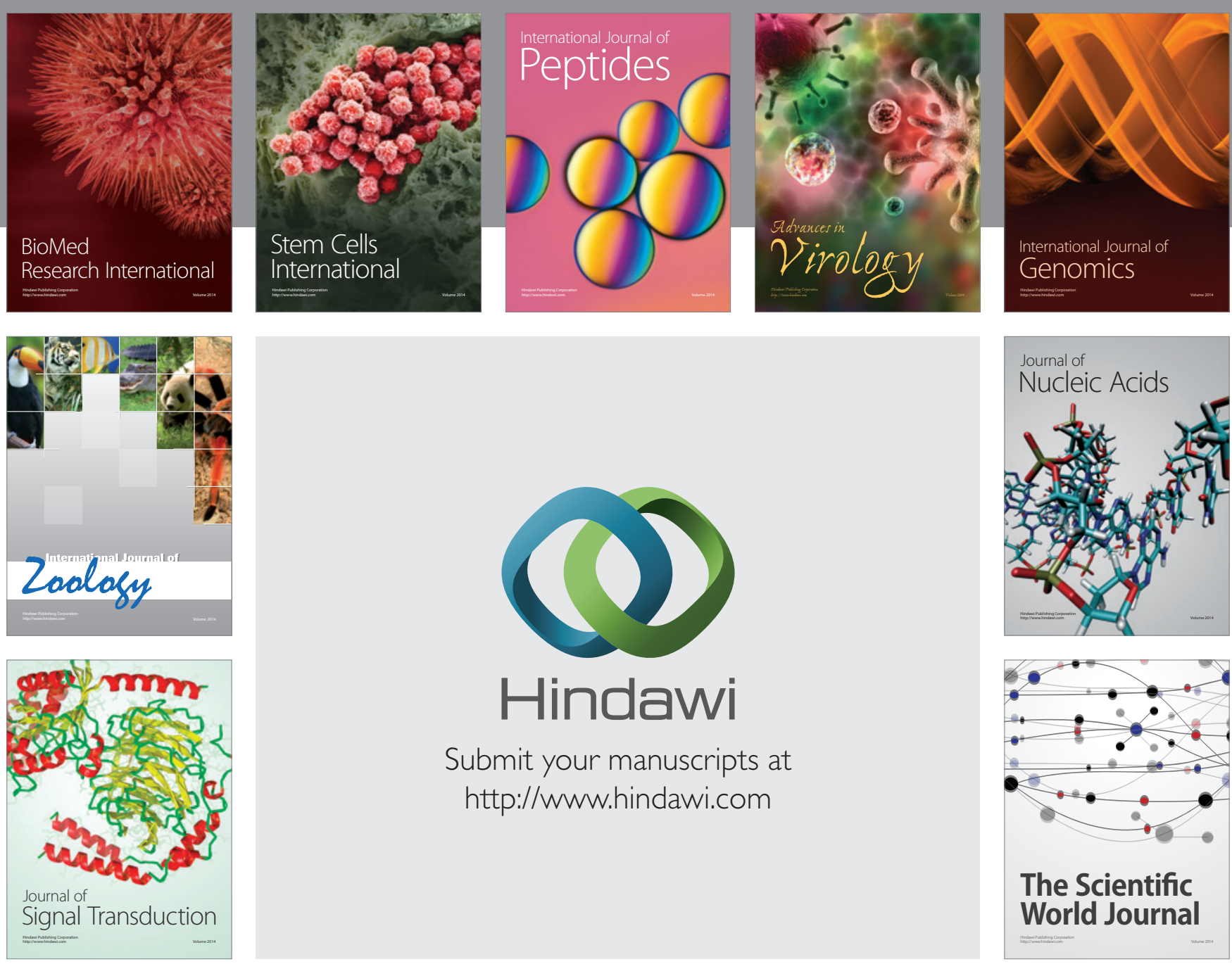

Submit your manuscripts at

http://www.hindawi.com
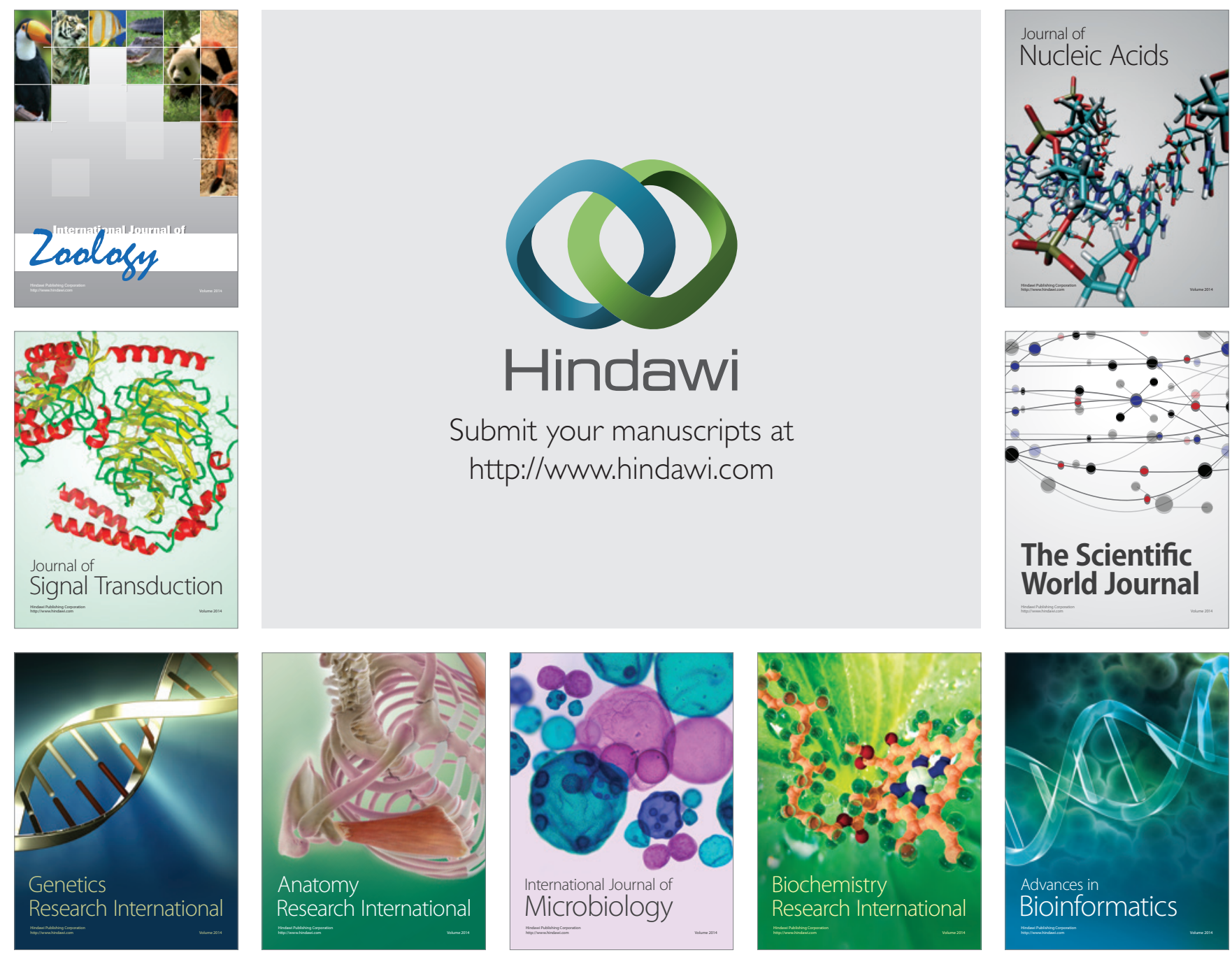

The Scientific World Journal
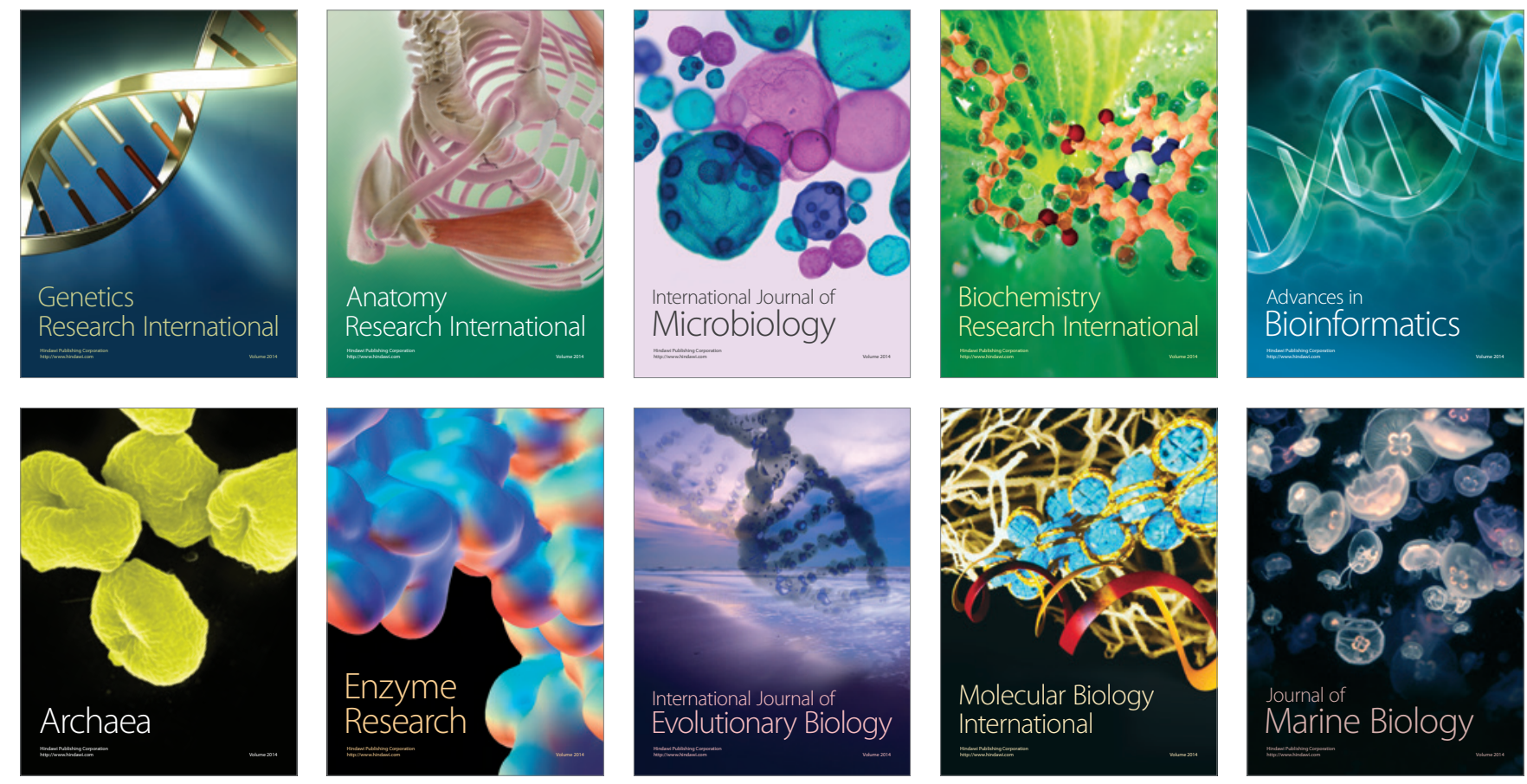